\title{
BMJ Open Early postdisaster health outreach to modern families: a cross-sectional study
}

\author{
Jon Magnus Haga, ${ }^{1,2}$ Lise Eilin Stene, ${ }^{1,3}$ Tore Wentzel-Larsen, ${ }^{1,4}$ Siri Thoresen, ${ }^{1}$ \\ Grete Dyb $b^{1,2}$
}

To cite: Haga JM, Stene LE, Wentzel-Larsen T, et al. Early postdisaster health outreach to modern families: a crosssectional study. BMJ Open 2015;5:e009402.

doi:10.1136/bmjopen-2015009402

\section{- Prepublication history and additional material is available. To view please visit the journal (http://dx.doi.org/ 10.1136/bmjopen-2015- 009402).}

Received 15 July 2015 Revised 7 September 2015 Accepted 21 October 2015

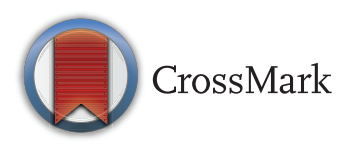

${ }^{1}$ Norwegian Centre of Violence and Traumatic Stress Studies, Oslo, Norway ${ }^{2}$ Faculty of Medicine, University of Oslo, Institute of Clinical Medicine, Oslo, Norway

${ }^{3}$ Department of Social Pediatrics, Women and Children's Division, Oslo University Hospital, Oslo, Norway

${ }^{4}$ Centre for Child and Adolescent Mental Health, Eastern and Southern Norway, Oslo, Norway

Correspondence to Jon Magnus Haga; jon.magnus.haga@medisin. uio.no

\section{ABSTRACT}

Objectives: This study investigated whether the early outreach programme following the Utøya massacre reached out to the parents of the young survivors. Additionally, we explored whether specialised mental healthcare services were provided to parents presenting elevated levels of PTSD and depression reactions.

Design: Cross-sectional survey, face-to-face interviews and questionnaires.

Setting: Norway, aftermath of the Utøya massacre, 4-7 months postdisaster.

Background: Following the Utøya massacre, proactive early outreach programmes were launched in all municipalities that were affected, facilitating access to appropriate healthcare services.

Participants: A total of 453 parents of the Utøya survivors aged 13-33 years took part. Overall, 59.8\% of the survivors were represented by one or more parent in our study.

Main outcome measures: Engagement with the proactive early outreach programme (psychosocial crisis teams and contact persons in the municipalities), utilisation of healthcare services (general practitioner and specialised mental healthcare services) and mental distress (UCLA PTSD-RI and HSCL-8).

Results: A majority of the participants reported contact with the proactive early outreach programme (crisis team, 73.9\%; and contact person, 73.0\%). Failure of outreach to parents was significantly associated with non-intact family structure (crisis team: OR 1.69, 95\% Cl 1.05 to 2.72, $p=0.032$ ) and non-Norwegian origin (crisis team: OR $2.39,95 \% \mathrm{Cl}$ 1.14 to $4.98, p=0.021$ ). Gender of the parent was not significantly associated with failure of the outreach programme $(p \geq 0.075)$. Provision of specialised mental healthcare services was significantly associated with higher levels of PTSD (OR 2.08, 95\% Cl 1.55 to 2.79, $\mathrm{p}<0.001$ ) and depression (OR 2.42, 95\% Cl 1.71 to $3.43, p<0.001$ ) and not with the sociodemography $(p \geq 0.122)$.

Conclusions: Proactive early outreach strategies may be helpful in identifying healthcare needs and facilitating access to the required services in a population struck by disaster. Our findings prompt increased attention to the complexity of family structures in reaching out universally to modern families following a disaster.

\section{Strengths and limitations of this study}

- The nature of the traumatic exposure, the ordered aftermath, and the perfect separation of parents and survivors allow the assessment of indirect exposure of families to terrorism.

- We were able to recruit a high number of caregivers, including multiple caregivers of the majority of the survivors and high numbers of paternal caregivers.

- Our figures represent the combined picture of crisis response programmes in a total of $n=128$ municipalities.

- A majority of the data was collected in face-toface interviews with experienced clinicians.

- All analyses are correlational. No causality can be demonstrated.

\section{INTRODUCTION}

In the summer of 2011, Norway experienced a terrorist attack on a summer camp of political youth, gathered on a small island, Utøya, for political workshops and social recreation. One single perpetrator, responsible for the bombing of the governmental quarters $<2 \mathrm{~h}$ earlier, started a shooting spree immediately on his arrival to the island. The youth were trapped with the perpetrator on the island for more than $1 \mathrm{~h}$ with no means of selfdefence, limited access to shelter and scarce chances of escaping. The attack left 69 dead. Nearly 500 survived, of which 35 sustained severe physical injuries. Parents, siblings, relatives and friends were confined to live media reports as the atrocities unfolded. Following the attack, all survivors were returned to their families in communities across all regions of Norway.

Persistent mental ill-health, notably posttraumatic stress disorder (PTSD) and depression, may frequently trouble survivors of terrorism for years following the trauma. ${ }^{1}{ }^{2}$ Recent terrorism specifically targeting children and adolescents have prompted particular attention to the impact of terrorism on youth. $^{3-6}$ However, terrorism may have 
detrimental effects not only on those directly exposed, but also on their close ones, particularly their parents. Studies of parents caring for chronically ill $^{7} 8$ and acutely ill ${ }^{9}{ }^{10}$ children and children exposed to sexual abuse $^{11}$ have demonstrated high levels of PTSD and depression. Analogously, studies on parents of UN peacekeepers and mothers of US military personnel deployed to Iraq have demonstrated substantial distress years following redeployment of offspring from hostile environments. $^{12} 13$ Indirect impact of terrorism on parents of young survivors is, however, still largely unaddressed.

In order to facilitate access to appropriate care and minimise unmet healthcare needs in a population affected by a disaster, evidence-informed recommendations for proactive early outreach have been made in a number of recent consensus documents. ${ }^{14-16}$ Early outreach may target unmet needs by providing initial psychosocial and practical support, monitoring healthcare needs, and facilitating access to healthcare services. ${ }^{17-19}$ In contrast to regular healthcare, the idea of outreach is to engage proactively and universally with the population of target, with regard neither to medical history nor to levels of distress. However, the recommendations do not address the needs of the indirectly exposed families of the terror victims.

Following the shooting in Utøya, a national proactive early outreach programme was established. The programme included both municipal interdisciplinary psychosocial crisis teams and a designated contact person for each survivor, their families and the families of the deceased. Crisis teams were to contact all affected families promptly following the attack and offer initial support. The contact persons were to monitor healthcare needs throughout the first year following the attack through a minimum of three waves of formalised screening assessments at 5-6 weeks, 3 months and 1 year. The geographical dispersion of the survivors of the terrorist attack warranted implementation of early outreach programmes in a total of 128 municipalities of all five regions of the country.

Modern families frequently diverge from that of cohabiting mothers and fathers, and pose particular challenges for outreach to parents of young survivors. Divorce of parents, introduction of step-parents and presence of half-siblings and step-siblings give rise to variability in the number of caregivers, number of households and gender composition of households of modern families. Gender roles in transition and ethnic and cultural diversity may further add to the complexity of modern family arrangements and challenge implementation of outreach strategies. In regular practice, healthcare providers are inexperienced with initiating contact with individuals who are not already in touch with the healthcare services and may be unfamiliar with the variability of modern family structures. Healthcare providers may be reluctant to engage proactively and indiscriminately with a target population, rather than individual patients, and may perhaps be prone to favouring individuals with registered health problems. Moreover, for ethnic minorities, proactive outreach may potentially be postponed or indeed neglected due to inexperience with or constraints to access to interpreters or bilingual healthcare providers.

The aims of this study were to investigate whether the early outreach programme following the Utøya shooting reached out to the parents of the survivors and whether it reached out equally well to mothers and fathers, traditional and non-traditional family structures, parents of both Norwegian and non-Norwegian origin, and across different levels of distress. Additionally, we explored whether specialised mental healthcare services (MHS) were indeed provided to those presenting elevated levels of PTSD and depression reactions.

\section{METHODS \\ Design}

This cross-sectional study assessed outreach and healthcare to the parents/caregivers of the youth survivors (13-33 years) of the 2011 Utøya summer camp massacre at 4-7 months following the terror attack.

\section{Procedures}

Invitations to participate in the study were sent to the addresses of the survivors. Subsequently, the survivors were contacted by telephone and asked about the contact information of their caregivers. The caregivers identified by the survivors were then contacted and asked if they were willing to participate in the study. All caregivers are referred to as parents, without regard to their legal, social or biological status or number of caregivers nominated per family.

Invitations were distributed through mail which included general information about the study and on how to opt out. Parents of the survivors born in 1992 or later were invited to participate in individual semistructured face-to-face interviews by healthcare professionals in their own homes or in an alternative location at the request of the participant. The interviewers were trained in a 1-day session prior to conducting interviews. The interviews lasted approximately $1 \mathrm{~h}$ and were audiotaped. Parents of older survivors (born in 1991 or earlier) and parents who were not available for an interview participated by questionnaires. Information on sociodemographic variables, contact with the early outreach programme and the utilisation of healthcare services were collected through questionnaires for all parents, either at the end of the interview or as a part of the postal questionnaire. Interviews started early November 2011 and were largely completed $(>95 \%)$ by mid-December 2011, 5 months after the attacks. Questionnaires were distributed by mail at the time of the interviews. By mid-February 2012, 95\% of the data of both modalities had been collected. 
All participants provided a written consent. The study was approved by the Regional Committees for Medical and Health Research Ethics in Norway.

\section{Participants}

The police records of survivors recovered from Utøya included a total of 495 names. Parents of older survivors ( $>33$ years of age, $\mathrm{N}=8$ ), parents of the youngest survivors $(<13$ years, $\mathrm{N}=4)$ and parents of one survivor settled abroad were not invited to the study. In total, parents of 482 survivors were eligible participants of this study.

A total of 453 parents from 270 families, representing $59.8 \%(\mathrm{n}=288)$ of the survivors of Utøya (aged 1333 years) participated, of which 16 families had more than one child in Utøya. A majority of the 270 families participated with two parents or more $(65.9 \%, \mathrm{n}=178)$. In nearly half of the families, parents were divorced or separated (43.0\%, $\mathrm{n}=116)$. Divorced, non-cohabiting parents were recorded as separate households. A total of 315 distinct households were identified. Households were subdivided into 'intact family' (parents not divorced), 'blended household' (parent divorced, new partner) and 'single household' (parent divorced, no new partner). Norwegian origin, survivors' affiliation with the Worker's Youth League/Labor Party (the political party being targeted through the attacks), young age of offspring survivor and shared accommodation with offspring survivor favoured parental participation (see online supplementary table S1). Addressing the mode of participation, we found that paternal caregivers and caregivers of non-intact families were more likely to be unavailable for participation through face-to-face interviews than maternal caregivers and intact families (see online supplementary table S2). Neither measure of distress was significantly associated with mode of participation.

\section{Measures}

Proactive early outreach was assessed by two items: 'Did anyone from the crisis team or other representative of the municipality contact you right after the event?' (yes/ no) and 'Have you had a contact person in the municipality?' (yes/no).

Health service utilisation was assessed by inquiring about whether the subject any time following the events in Utøya received care from a regular general practitioner (GP, yes/no) or psychiatrist or psychologist in specialised MHS (yes/no).

Traumatic stress exposure of all parents included having an offspring threatened with violent death in Utøya. Additional exposure was assessed by inquiring at what time the parent was informed about the condition of his/her offspring, and at what time they were reunited (date and time). Additionally, we inquired about telephone contact (voice or text) with offspring while the shooting was ongoing (yes/no), physical injury and hospitalisation of offspring (yes/no), hospitalisation of a close friend or family member (yes/no), fatality of a close friend or family member (yes/no) and whether the parent, at the time of the Utøya attack, had concurrent concerns about family or friends being affected by the bombing of the Government Quarter in Oslo that had taken place earlier in the day (yes/no).

Post-traumatic stress reactions (PTSR) during the past month were evaluated by the 20-item University of California, Los Angeles PTSD Reaction Index (UCLA PTSD-RI ${ }^{20}$ according to the Diagnostic and Statistical Manual of Mental Disorders (DSM IV). ${ }^{21}$ Responses were recorded on a five-point Likert-type scale, ranging from 0 (never) to 4 (most of the time). Three of the items had two alternative formulations, with the highest frequency score used to calculate the total score. Hence, 17 scores constituted the total symptom scale score (possible range 0-68). Criterion A (exposure to potentially traumatic event) was satisfied in all participants of this study. Criteria B (intrusion), C (avoidance) and D (arousal) were derived by grouping items related to these categories. Inquiries on PTSR were formulated so as to explicitly relate to the terrorist attack. Scores of 3 (often) and 4 (most of the time) of each item were taken to indicate presence of a clinical symptom. Probable PTSD diagnosis (full PTSD) was considered on all diagnostic criteria being satisfied (ie, criterion $\mathrm{A}, \geq 1$ item criterion $\mathrm{B}, \geq 3$ items criterion $\mathrm{C}$ and $\geq 2$ items criterion D). With two criteria being satisfied, partial PTSD was considered in patients falling short of full diagnosis. Full and partial probable diagnoses were taken to represent clinically significant distress. Cronbach's $\alpha$ of the total scale was 0.92 .

Symptoms of depression and anxiety during the past 2 weeks were evaluated with an 8-item version of the Hopkins Symptom Checklist-25 (HSCL-25). ${ }^{22}$ Responses were recorded on a four-point Likert-type scale, ranging from 1 (not at all bothered) to 4 (very much bothered). Average scores of all 8 items were calculated for each parent. Short versions of the HSCL-25 have previously been used in Norwegian population surveys and have shown high correlations with the 25-item scale and good psychometric properties. ${ }^{23}{ }^{24}$ The subscale HSCL-5 was employed to identify clinically significant distress, with a clinically validated cut-off of $\geq 2.0$. Cronbach's $\alpha$ of the total scale was 0.90 .

Sociodemographic variables included age at the time of attack, country of birth (Norwegian/non-Norwegian origin), level of education (none, primary, secondary, vocational or higher education/university degree), current employment $\geq 50 \%$ (yes/no), and absence from work during the past 3 months (yes/no). Financial situation was assessed on a five-point Likert-type scale, where the parents rated the economy relative to the general population, ranging from 1 ('much better') to 5 ('much worse'). The responses were dichotomised into 'average or better' and 'below average'. Participants born outside Norway were considered to be of non-Norwegian origin and thus, as an ethnic minority in 
Norway. Most non-Norwegian participants in our study were born outside of Europe.

Information on cohabitation of parent and survivor (yes/no), age of offspring survivor, and affiliation with the Worker's Youth League/Labor Party (yes/no) was collected from a set of interviews with the survivors that were conducted in parallel with this study. ${ }^{3}$

\section{Statistics}

Point estimates of continuous data are reported by the mean or median value, with dispersion reported by SD and IQR. Logistic regression was used for bivariate analyses of categorical variables.

Missing values of the data set remained $\leq 5 \%$ throughout analyses, unless stated otherwise. Missing values $\leq 25 \%$ within sum scores of PTSD and HSCL-8 were resolved through calculations of mean scores of the remaining items.

On the basis of the hypotheses generated a priori, we designed a total of three logistic regression models. The first two models investigated proactive early outreach. The third model investigated specialised mental healthcare. Degrees of freedom available for each model were based on the number of observations in the smallest groups of the dependent variables. Clustering of members of the same families was addressed by the geeprocedure with an exchangeable correlation structure in the regression analyses (simplified when necessary for model stability). Independent variables of all models included gender (male/female), family structure (intact/non-intact), age, education (higher education/ no higher education), ethnicity (Norwegian/nonNorwegian origin), PTSR and HSCL-8. Multicollinearity of independent variables was assessed independently of the family clustering and identified by pair-wise correlation coefficients $(r)$ and variance inflation factors (VIF). As multicollinearity of PTSD-RI and HSCL-8 $(\mathrm{r}=0.82)$ was observed, the adjusted regressions of PTSD-RI and HSCL-8 were estimated without reciprocal adjustment to one another. The adjusted regressions of PTSD-RI and HSCL-8 thus include the sociodemographic variables of each model only. Adjusted regressions for the remaining variables of each model include the complete set of variables with both measures of psychopathology. Null hypotheses were rejected at significance levels of $\mathrm{p} \leq 0.05$.

Regression analyses were performed with R V.3.0.3 ( $R$ Foundation for Statistical Computing), with the package gee for gee analysis. Descriptive statistics were performed using SPSS statistics V.20, IBM.

\section{RESULTS}

The 453 parents who participated in this study were of both genders (males $43.3 \%, \mathrm{n}=196$ ) with a mean age of 48.3 years $\quad(\mathrm{SD}=6.55)$, largely of Norwegian origin $(98.1 \%, \mathrm{n}=413$, missing $\mathrm{n}=4)$, and residing in all regions of Norway at the time of the attack. The participants were well educated, with more than half $(57.8 \%, \mathrm{n}=260$, missing $\mathrm{n}=6$ ) of the parents holding a university degree, and they reported high employment rates $(89.5 \%$, $\mathrm{n}=400$, missing $\mathrm{n}=6$ ) with largely on average or above average financial situations $(87.0 \%, n=388$, missing $n=8)$. The majority of the participants were identified as biological parents $(95.6 \%, \mathrm{n}=433)$. Nevertheless, a great heterogeneity of family arrangements were identified (table 1), and nearly half of the 270 families represented by the parent participants were of a category other than intact nuclear families, with two cohabiting biological parents $(43 \%, \mathrm{n}=116)$.

Traumatic exposure of the parents included having a child threatened by violent death in Utøya. Moreover, more than half of the parents reported having had telephone contact with their offspring while the shooting was ongoing $(58.2 \%, \mathrm{n}=263$, missing $\mathrm{n}=1)$. Concurrent concerns of family or friends being affected by the bombing attack on the Government Quarter was reported by $39 \% \quad(n=176$, missing $n=2)$. Median time from the onset of the attacks until parents were informed on the condition of their offspring was $2.6 \mathrm{~h}$ $(\mathrm{IQR}=2.1-3.4 \mathrm{~h}$, missing $\mathrm{n}=25)$. Within $5 \mathrm{~h}, 90.7 \%$ $(n=388)$ of the parents had got such information. A majority of the survivors $(79.9 \%, \mathrm{n}=362$, missing $\mathrm{n}=4$ ) were reunited with their families within the following day. In the aftermath of the terrorist attack in Utøya, hospitalisation of offspring was experienced by $18.8 \%$ ( $\mathrm{n}=82$, missing $=17)$ of the parents. Moreover, physical injury to other family/close friend resulting in hospitalisation $(11.2 \%, n=49$, missing $n=17)$ or in fatality (17.5\%, $n=79$, missing $n=2$ ) added to the trauma of the parents.

The mean score of PTSR was 1.13 (range: 0-4, $\mathrm{SD}=0.76,95 \%$ CI 1.06 to 1.20 , missing $\mathrm{n}=2$ ). Partial PTSD was reported by $18.3 \%(n=83)$ and full PTSD by $7.1 \%(\mathrm{n}=32)$ of the parents. The mean score of depression was 1.69 (range: $1-4, \mathrm{SD}=0.63,95 \%$ CI 1.63 to 1.75 , missing $\mathrm{n}=4)$, with $28.9 \%(\mathrm{n}=133)$ scoring above the cut-off of $\geq 1.85$. Nearly half of the parents reported

Table 1 Parent participants by gender, type of caregiver and family structure $(n=453)$

\begin{tabular}{llll}
\hline & \multicolumn{2}{l}{ Gender } & \\
\cline { 2 - 3 } & Female & Male & \multicolumn{1}{l}{ Total } \\
\hline All & $257(56.7 \%)$ & $196(43.3 \%)$ & $453(100 \%)$ \\
Caregiver & & & \\
$\quad$ Biological & $251(97.7 \%)$ & $182(92.9 \%)$ & $433(95.6 \%)$ \\
Household* & & & \\
$\quad$ Intact family & $146(56.8 \%)$ & $130(66.3 \%)$ & $276(60.9 \%)$ \\
$\quad$ Blended & $51(19.8 \%)$ & $40(20.4 \%)$ & $91(20.1 \%)$ \\
$\quad$ Single & $58(22.6 \%)$ & $26(13.3 \%)$ & $84(18.5 \%)$ \\
$\quad$ Other & $2(0.8 \%)$ & & $2(0.4 \%)$ \\
\hline
\end{tabular}

*Intact family: cohabiting mother and father; blended and single households: divorced or widowed parents with or without new partner. 
Table 2 Overview of proactive early outreach and the use of health services by the parents $(n=429-448)$

\begin{tabular}{|c|c|c|c|c|}
\hline & \multicolumn{2}{|c|}{ Proactive early outreach } & \multicolumn{2}{|c|}{ Healthcare services } \\
\hline & Crisis team & Contact person & $\overline{\text { GP }}$ & MHS \\
\hline \multicolumn{5}{|c|}{ Dichotomous variables (number; \%, yes) } \\
\hline All parents & 331 (73.9) & $324(73.0)$ & $206(47.0)$ & $146(34.0)$ \\
\hline Mothers & $200(77.8)$ & $190(75.1)$ & $151(60.2)$ & $91(37.6)$ \\
\hline Fathers & $131(68.6)$ & $134(70.2)$ & $55(29.4)$ & $55(29.4)$ \\
\hline Parent of intact family & $210(77.2)$ & $211(78.4)$ & $121(45.7)$ & 94 (36.3) \\
\hline Parent of other family & $121(68.8)$ & $113(64.6)$ & $85(49.1)$ & $52(30.6)$ \\
\hline Norwegian origin & $310(75.2)$ & $304(74.1)$ & $187(46.5)$ & $131(33.3)$ \\
\hline Non-Norwegian origin & $20(57.1)$ & $19(57.6)$ & $18(51.4)$ & $14(40.0)$ \\
\hline Higher education & $190(73.4)$ & $184(71.6)$ & $117(46.2)$ & $91(35.8)$ \\
\hline No higher education & $140(74.5)$ & $139(74.7)$ & $88(47.8)$ & $54(31.0)$ \\
\hline \multicolumn{5}{|c|}{ Continuous variables (mean, yes vs no) } \\
\hline Age (years) & 48.1 vs 48.9 & 48.1 vs 48.8 & 47.2 vs 49.1 & 47.4 vs 48.6 \\
\hline PTSD: range $0-4$ & 1.15 vs 1.04 & 1.13 vs 1.09 & 1.36 vs 0.92 & 1.38 vs 0.98 \\
\hline HSCL-8: range $1-4$ & 1.71 vs 1.66 & 1.69 vs 1.68 & 1.92 vs 1.49 & 1.92 vs 1.57 \\
\hline
\end{tabular}

absence from work in the aftermath of the attacks due to health problems $(41.5 \%, \mathrm{n}=161$, missing $\mathrm{n}=12)$.

Table 2 summarises variables that were hypothesised to be associated with early outreach and the use of healthcare services. Although the programme of early proactive outreach engaged with a majority of the parents, paternal caregivers and parents of non-intact families and of non-Norwegian origin reported to have less frequently received outreach by their municipalities. Consultation with their regular GP following the attacks was reported by nearly half of the parents; this was more prevalent among women than men. Moreover, a third reported contact with specialised MHS. We found that proactive early outreach by a contact person was significantly associated with utilisation of a GP (OR 1.70, $\chi^{2}$ $\mathrm{p}=0.016$ ), but not of specialised MHS (OR 1.03, $\chi^{2}$ $\mathrm{p}=0.899)$.

A series of three adjusted regression models tested the variables hypothesised to be associated with early outreach and the use of specialised healthcare services.

Models A and B (figure 1A, B) tested associations of variables that were hypothesised to be associated with receiving proactive early outreach. Female gender was significantly associated with having been contacted by a crisis team in unadjusted regression. In adjusted multivariable analyses, however, intact family structure, but not gender, was significantly associated with having been included in both forms of proactive early outreach, and non-Norwegian origin was significantly associated with having been contacted by the crisis teams. Stress reactions, on the other hand, were not significantly associated with engagement with the proactive outreach programme.

Model C (figure 1C) tested associations of variables that were hypothesised to be associated with utilisation of specialised MHS. Utilisation of specialised MHS was significantly associated with PTSR and depression, but not with either of the sociodemographic variables included in our study.

Finally, we assessed utilisation of specialised healthcare services among parents with the highest levels of distress. Clinically significant levels of distress defined as partial or full PTSD or HSCL-5 above cut-off were taken to indicate the need for healthcare services. Although, clinically significant distress and the use of specialised healthcare services were reported by nearly equivalent numbers of parents $(35.1 \%, \mathrm{n}=158$, missing $\mathrm{n}=3$ vs $34 \%$, 146 , missing $\mathrm{n}=24$ ) and the use of GP was reported by nearly half of the parents $(47 \%, \mathrm{n}=206$, missing $\mathrm{n}=15)$, a total of $8.3 \%$ of the parents reported a combination of significant distress and no contact with any healthcare service $(n=36)$ (table 3). Reversely, a total of $33.6 \%$ of the parents reported utilisation of healthcare services without presenting distress at the time of data collection $(n=146)$.

\section{DISCUSSION}

Crisis response typically focuses on survivors of a disaster and may easily overlook affected individuals not present at the site of an attack. The first aim of this study was to investigate whether the early outreach following the Utøya shooting managed to reach the parents of the young survivors. Our data suggest that the outreach programme succeeded in reaching out to a large proportion of the parents, and that the programme engaged equally well with mothers and fathers. Encouragingly, the outreach was not significantly associated with levels of either PTSR or depression, in line with the principle of universal early outreach. However, modern families are heterogeneous and changeable. Nearly half of the parents in our sample were of a category other than that of a traditional cohabiting mother and father. The outreach following Utøya failed in engaging with parents who did not live together and parents of ethnic 
UNADJUSTED $(-1-)$ ADJUSTED ( $(-)$

\section{A Crisis team}

- missing (total) $n=8,1.8 \%$

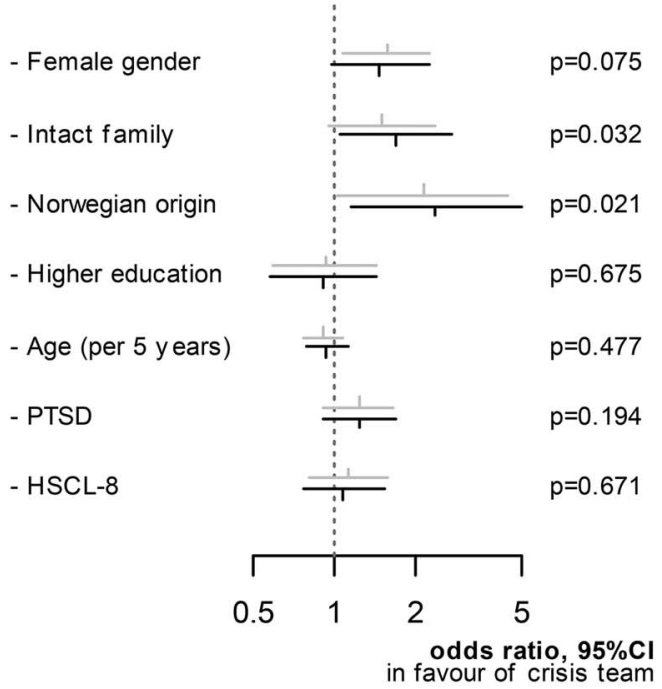

B Contact person

- missing (total) $n=12,2.6 \%$

- Female gender

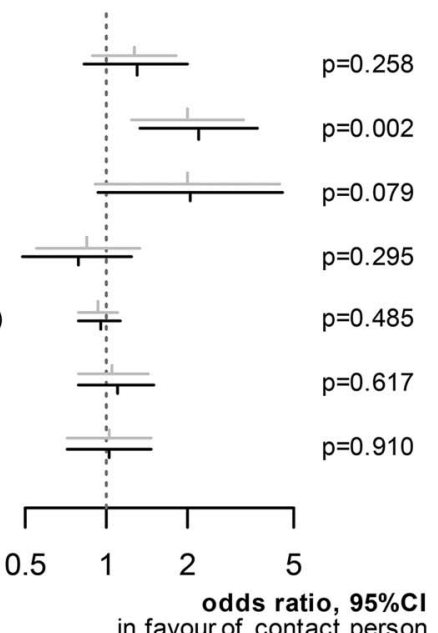

in favour of contact person

- Intact family

- Norwegian origin

- Higher education

- Age (per 5 years)

- PTSD

- HSCL-8

C Specialised mental healthcare

- missing (total) $n=28,6.2 \%$

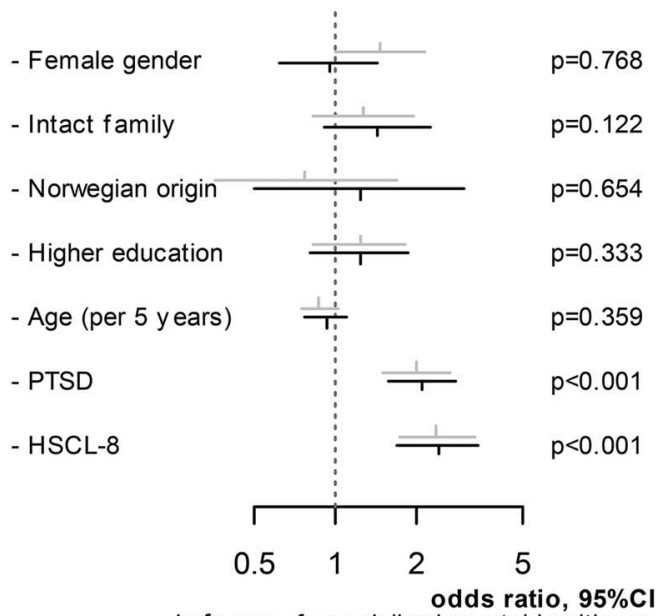

in favour of specialised mental healthcare
Figure 1 Logistic regression models of proactive early outreach (crisis team (A), contact person (B) and specialised mental healthcare services (C)). Adjusted regressions include all independent variables of each model. As multicollinearity of PTSD-RI and HSCL-8 ( $r=0.82)$ is observed, the adjusted regressions of PTSD-RI and HSCL- 8 are estimated without reciprocal adjustment to one another. The adjusted regressions of PTSD-RI and HSCL-8 thus include the sociodemographic variables of each model only. Adjusted regressions for the remaining variables of each model include the complete set of variables with both measures of psychopathology. All models are adjusted for clustering of members of the same families. p-values of the adjusted estimates are reported. Complete numbers are available in online supplementary table S3a-c.

minorities. Thus, our results suggest that families diverting from the norm may be susceptible to being left out of proactive crisis response.

Having a child seriously injured or threatened with violent death may be traumatising to parents. Inability of parents in coming to their child's rescue and the uncertainty awaiting news on their child may add to the trauma. Following the Utøya attack, high levels of PTSR, depression, and sick leave were observed. We speculate that the combination of indirect trauma victimhood of parents and the role as caregiver of a directly exposed victim may pose particular challenges to parents following a disaster, impacting negatively both on parental health and on their ability to provide care. In Norway, a life-time prevalence of PTSD of $2.6 \%$ has previously been reported in a sample of 2794 Norwegian adult twins. ${ }^{25}$ Although the sample may not be considered representative of the Norwegian adult population, the findings are largely consistent with overall European figures. ${ }^{26}$ When compared to a concurrent populationbased study of post-traumatic stress in the early aftermath of the attack, ${ }^{27}$ our data suggest levels of PTSR several times higher among the parents of the Utøya survivors than in the general Norwegian population at the time. Bridging the gap between the needs of parents affected by trauma, on the one hand, and the healthcare services available to them, on the other hand, may thus be of essence both in promoting the health of the parents, and also in strengthening the self-care capabilities of the affected family. An increased awareness of potential barriers to outreach may prove critical to the success of future crisis responses.

The second aim of this study was to explore whether specialised MHS following the Utøya shooting were indeed provided to parents in need. Our data suggest that engagement with a contact person was associated with the use of a GP, the entry point of the Norwegian healthcare system, but not with specialised MHS. Specialised MHS were significantly associated with levels of PTSR and depression alone. Our results suggest that early outreach may have facilitated access to healthcare services, but that referrals to specialised MHS were reserved for parents in need of such care. 
Table 3 Parental distress and the use of healthcare services (percentages of total, $n=435$ )

\begin{tabular}{cccc}
\hline & \multicolumn{2}{l}{ Healthcare services* } & \\
\cline { 2 - 3 } & Yes & No & Total \\
\hline Distresst & & & \\
Yes & $115(26.4 \%)$ & $36(8.3 \%)$ & $151(34.7 \%)$ \\
No & $146(33.6 \%)$ & $138(31.7 \%)$ & $284(65.3 \%)$ \\
Total & $261(60.0 \%)$ & $174(40.0 \%)$ & $435(100 \%)$ \\
\hline
\end{tabular}

${ }^{*}$ General practitioner and/or specialised mental healthcare services.

†Psychological distress reactions above cut-offs of the UCLA PTSD-RI (partial or full) and/or HSCL-5 ( $\geq 2.0)$.

Potentially unmet healthcare needs were considered in parents reporting significant distress and no healthcare services. This figure must be interpreted cautiously, as the parents may indeed have enjoyed other healthcare services than those addressed in our study. Moreover, lack of distress does not disprove a need for healthcare services, as the parents may have presented other healthcare needs than those addressed in our study, including somatic healthcare needs, as well as needs unrelated to the terrorist attack. Additionally, early distress may have prompted utilisation of healthcare services at an early stage, even if the distress was no longer present at the time of data collection. The figure may thus include a number of parents having benefitted from timely healthcare services.

Our data suggest relatively low numbers of parents presenting with a combination of clinically significant distress and no healthcare services. However, provision of healthcare services is no guarantee of covering the needs in patients, as services may be of suboptimal quality. Still, our data may reflect success of the postdisaster healthcare response in reaching out to a majority of the parents. A qualitative study suggests that a number of parents presented non-healthcare-related needs following the attack, including follow-up from school, workplace, practical support and professional counselling. ${ }^{28}$ Future studies would benefit from exploring both the long-term trajectories of health and the range of healthcare and nonhealthcare related needs that may arise post disaster.

\section{Strengths and limitations}

The Utøya attack unfolded in an otherwise deserted place, with a fairly homogenous exposure, within a limited spatiotemporal frame and with a fixed population of young individuals. The aftermath of the attack allowed for complete identification of all survivors of the attack and with few constraints to immediate evacuation to appropriate healthcare facilities. The nature of the exposure, the ordered aftermath, and the perfect separation of parents and survivors add validity to our model of indirect exposure to terrorism. Moreover, we were able to recruit a high number of caregivers, including multiple caregivers of the majority of the survivors, and a high number of paternal caregivers. The parent sample thus enables a detailed understanding of the individual family structures; however, the full size of the parent population remains unknown.

In many cases of terror and natural disaster, victims and their families may be hard to identify. In the case of Utøya, the survivors were all identified by the police when rescued from the island. Moreover, prior to the terror attack, most Norwegian municipalities had already established functional crisis teams dealing with smaller scale events such as families bereaved from suicide, car accidents and sudden deaths. The municipalities thus had both infrastructure and experience in reaching out proactively to families. Nevertheless, as our figures represent the combined picture of crisis responses of $n=128$ municipalities, the outreach is likely to have varied across the country. Thus, the data reflect the overall national strategy of proactive early outreach, rather than experiences from a single adaptation of such a strategy.

The two measures of proactive outreach, crisis team and contact person, were established independently of one another and served distinct aims. Nevertheless, overlap of personnel between the measures may have occurred. The number or length of contacts with the crisis team is not known. Contact persons were to have a minimum of three contacts during the first year. More information regarding the nature and extent of the contact between families and outreach services would have been preferable. The interview covered a wide range of variables, and we had to limit the interview length in this early phase postdisaster. The context of this study is a universal and publicly funded healthcare system. The results may thus be most applicable in the context of similar healthcare systems.

The quality of data collected was good with respect to high overall response rates and low levels of missing data. Although a majority of the data was collected in face-to-face interviews with experienced clinicians, all data represent self-reports by the patients. No adjustments to variation in mode or time of data collection were made. All analyses are correlational. No causality can be demonstrated. We made no evaluation of the contents of the contacts with the healthcare services, treatment efficacy or quality of life.

\section{CONCLUSION}

Following the Utøya terrorist attack, healthcare services were offered to parents presenting with elevated levels of distress. Still, our data suggest that healthcare needs in a number of parents presenting with high levels of distress were not met. Outreach strategies may be helpful in identifying healthcare needs and in facilitating access to healthcare services following a disaster. This study shows that particular attention to the complexity of family structures and ethnic diversity is critical in reaching out to modern families.

Twitter Follow Jon Magnus Haga at @sungam_noj 
Acknowledgements The authors thank the participants for their invaluable contribution to this study and the health professionals all across Norway for assisting in the data collection.

Contributors GD and ST had the original idea for the study and developed the study design with LES, TW-L and JMH. GD, ST, LES and JMH interviewed participants. TW-L and JMH carried out the quantitative analyses. JMH wrote the first draft of the paper. All authors contributed to further drafts. JMH is the guarantor.

Funding The research was funded by grants from the Norwegian Research Council and the Norwegian Directorate of Health.

\section{Competing interests None declared}

Ethics approval The study was approved by the Regional Committees for Medical and Health Research Ethics in Norway.

Provenance and peer review Not commissioned; externally peer reviewed.

Data sharing statement No additional data are available.

Open Access This is an Open Access article distributed in accordance with the Creative Commons Attribution Non Commercial (CC BY-NC 4.0) license, which permits others to distribute, remix, adapt, build upon this work noncommercially, and license their derivative works on different terms, provided the original work is properly cited and the use is non-commercial. See: http:// creativecommons.org/licenses/by-nc/4.0/

\section{REFERENCES}

1. Salguero JM, Fernández-Berrocal P, Iruarrizaga I, et al. Major depressive disorder following terrorist attacks: a systematic review of prevalence, course and correlates. BMC Psychiatry 2011;11:96.

2. DiMaggio $\mathrm{C}$, Galea $\mathrm{S}$. The behavioral consequences of terrorism: a meta-analysis. Acad Emerg Med 2006;13:559-66.

3. Dyb G, Jensen TK, Nygaard E, et al. Post-traumatic stress reactions in survivors of the 2011 massacre on Utøya Island, Norway. Br J Psychiatry 2014;204:361-7.

4. Suomalainen $\mathrm{L}$, Haravuori $\mathrm{H}$, Berg $\mathrm{N}$, et al. A controlled follow-up study of adolescents exposed to a school shootingpsychological consequences after four months. Eur Psychiatry 2011;26:490-7.

5. Scrimin S, Axia G, Capello F, et al. Posttraumatic reactions among injured children and their caregivers 3 months after the terrorist attack in Beslan. Psychiatry Res 2006;141:333-6.

6. Miron LR, Orcutt HK, Kumpula MJ. Differential predictors of transient stress versus posttraumatic stress disorder: evaluating risk following targeted mass violence. Behav Ther 2014;45:791-805.

7. Vanderwerker LC, Laff RE, Kadan-Lottick NS, et al. Psychiatric disorders and mental health service use among caregivers of advanced cancer patients. J Clin Oncol 2005;23:6899-907.

8. Cabizuca M, Marques-Portella C, Mendlowicz MV, et al. Posttraumatic stress disorder in parents of children with chronic illnesses: a meta-analysis. Health Psychol 2009;28:379-88.

9. Schmidt M, Azoulay E. Having a loved one in the ICU: the forgotten family. Curr Opin Crit Care 2012;18:540-7.
10. Nelson LP, Gold JI. Posttraumatic stress disorder in children and their parents following admission to the pediatric intensive care unit: a review. Pediatr Crit Care Med 2012;13:338-47.

11. Dyb G, Holen A, Steinberg AM, et al. Alleged sexual abuse at a day care center: impact on parents. Child Abuse Negl 2003;27:939-50.

12. Dirkzwager AJ, Bramsen I, Adèr $\mathrm{H}$, et al. Secondary traumatization in partners and parents of Dutch peacekeeping soldiers. J Fam Psychol 2005; 19:217-26.

13. Slaven-Lee PW, Padden D, Andrews CM, et al. Emotional distress and health risk behaviours of mothers of United States Marines. Int Nurs Rev 2011;58:164-70.

14. National Commission on Children and Disasters. 2010 Report to the President and Congress. AHRQ Publication, 2010.

15. Hobfoll SE, Watson P, Bell CC, et al. Five essential elements of immediate and mid-term mass trauma intervention: empirical evidence. Psychiatry 2007;70:283-315; discussion 6-69.

16. Bisson JI, Tavakoly B, Witteveen AB, et al. TENTS guidelines: development of post-disaster psychosocial care guidelines through a Delphi process. Br J Psychiatry 2010;196:69-74.

17. Call JA, Pfefferbaum B. Lessons from the first two years of Project Heartland, Oklahoma's mental health response to the 1995 bombing. Psychiatr Serv 1999;50:953-5.

18. Brewin CR, Fuchkan N, Huntley Z, et al. Outreach and screening following the 2005 London bombings: usage and outcomes. Psychol Med 2010;40:2049-57.

19. Stuber J, Galea S, Boscarino JA, et al. Was there unmet mental health need after the September 11, 2001 terrorist attacks? Soc Psychiatry Psychiatr Epidemiol 2006;41:230-40.

20. Steinberg AM, Brymer MJ, Decker KB, et al. The University of California at Los Angeles Post-traumatic Stress Disorder Reaction Index. Curr Psychiatry Rep 2004;6:96-100.

21. First MB. Diagnostic and statistical manual of mental disorders. DSM IV-4th edition APA p. 1994:97-327.

22. Solberg $\varnothing$, Dale MT, Holmstrøm $\mathrm{H}$, et al. Long-term symptoms of depression and anxiety in mothers of infants with congenital heart defects. J Pediatr Psychol 2011;36:179-87.

23. Strand $\mathrm{BH}$, Dalgard OS, Tambs K, et al. Measuring the mental health status of the Norwegian population: a comparison of the instruments SCL-25, SCL-10, SCL-5 and MHI-5 (SF-36). Nord J Psychiatry 2003;57:113-18

24. Tambs K, Moum T. How well can a few questionnaire items indicate anxiety and depression? Acta Psychiatr Scand 1993;87:364-7.

25. Amstadter AB, Aggen SH, Knudsen GP, et al. Potentially traumatic event exposure, posttraumatic stress disorder, and Axis I and II comorbidity in a population-based study of Norwegian young adults. Soc Psychiatry Psychiatr Epidemiol 2013;48:215-23.

26. Alonso J, Angermeyer MC, Bernert S, et al., ESEMeD/MHEDEA 2000 Investigators, European Study of the Epidemiology of Mental Disorders (ESEMeD) Project. Prevalence of mental disorders in Europe: results from the European Study of the Epidemiology of Mental Disorders (ESEMeD) project. Acta Psychiatr Scand Suppl 2004(420):21-7.

27. Thoresen S, Aakvaag HF, Wentzel-Larsen T, et al. The day Norway cried: Proximity and distress in Norwegian citizens following the 22nd July 2011 terrorist attacks in Oslo and on Utøya Island. Eur J Psychotraumatol 2012;3:19709.

28. Glad KA, Jensen TK, Dyb G. "Er det hjelp du har savnet etter terroranslaget på Utøya?» Foreldrene forteller. Tidsskr Nor Psykologfor 2014;51:537-45. 